\title{
ZIF polymorphs for Nucleic Acid Delivery and Targeted Knockdown of Gene Expression in Prostate Cancer
}

Arpita Poddar, ${ }^{\dagger}$ Suneela Pyreddy, ${ }^{\dagger}$ Francesco Carraro, ${ }^{*}$ Sudip Dhakal, ${ }^{\dagger}$ Andrea Rassell, ${ }^{\dagger}$ Matthew $R$. Field, ${ }^{\circledR}$ T. Srinivasa Reddy, ${ }^{\dagger}$ Paolo Falcaro, ${ }^{\#}$ Cara M. Doherty, ${ }^{\S}$ Ravi Shukla ${ }^{\dagger *}$

$\dagger$ Ian Potter NanoBiosensing Facility, NanoBiotechnology Research Laboratory (NBRL), School of Science, RMIT University, Melbourne, Victoria 3001, Australia

ๆ RMIT Microscopy \& Microanalysis Facility, RMIT University, Melbourne, Victoria 3001, Australia \# Institute of Physical and Theoretical Chemistry, Graz University of Technology, 8010 Graz, Austria § CSIRO Manufacturing, Clayton, Victoria 3168, Australia

ABSTRACT Prostate cancer (PC) is the second leading cause of male cancer deaths, the advanced form of which continues to be incurable; and nature of the disease being such that it is highly suitable for gene therapy. However, therapy is hampered by lack of appropriate gene delivery agents available. Recently, metal-organic-framework (MOF) biocomposites have seen increasing applications in DNA technologies, including gene delivery. In this work, a polymorph of zeolitic imidazolate framework-8 (ZIF-8) MOF nanoparticles called ZIF-C are used as gene delivery agents to cause knockdown (KD) of a protein overexpressed by the gene ribosomal protein SA in PC. Feasibility of ZIF-C mediated KD at cytoplasmic levels in PC is demonstrated by RNA interference, whereby RPSA specific siRNA is delivered using ZIF-C. Feasibility of ZIF-C mediated KD at genomic levels is demonstrated by CRISPR/Cas9, whereby RPSA specific CRISPR/Cas9 plasmids are delivered using ZIF-C. Specific targeting is further achieved by coating of ZIF-C with epigallocatechin-gallate (EGCG). Cellular transfection assays reveal the gradual expression of ZIF-C delivered RPSA-targeting nucleic acids for up to 96 hours. Quantitative polymerase chain reactions and genomic cleavage detection demonstrate gradual $\mathrm{KD}$, with $\sim 20 \%$ reduction in RPSA expression that is almost doubled to $\sim 40 \%$ on EGCGmediated targeted cellular uptake. 
Prostate cancer (PC) is the second-most common cancer in men that accounts for the fifth leading cause of male cancer deaths globally. ${ }^{[1,2]}$ Although there have been developments in therapeutic options, the unfortunate reality is that most of the available therapies are associated with major side effects like erectile dysfunction, urinary incontinence or bowel dysfunction and have shown limited ability to cure patients in the later stages of disease. ${ }^{[3]}$ Moreover, the progression to castration-resistant-PC is so far incurable and fatal. ${ }^{[4-6]}$ With an increasing record of global PC incidence, there is an urgent need to enhance treatment efficacy. ${ }^{[7]}$. Gene therapy is a new form of treatment aimed at altering or modifying expression of defective and/or missing gene sequences in diseases like cancer. ${ }^{[8]}$. It is a particularly suitable form of therapy for PC, firstly due to the anatomy of the prostate organ which allows ease in close monitoring of therapy regimen through digital rectal exam (DRE), ${ }^{[9]}$ trans urethral ultrasound (TRUS) probes, ${ }^{[10]}$ magnetic resonance imaging (MRI)/ positron emission tomography $(\mathrm{PET}),{ }^{[11]}$ and serum prostate specific antigen (PSA) ${ }^{[12]}$ testing. Secondly, physiology of the disease is such that PC has a long preclinical latency, providing time and scope for implementation of several therapeutic strategies. ${ }^{[13]}$ Thirdly, knowledge of the molecular basis of PC is clearer than it ever was before and the genetic basis for the molecular progression is being well studied and has provided viable targets for gene therapy. ${ }^{[14,15]}$ Finally, the prostate organ itself is nonessential after the reproductive age and PC is often accompanied by benign prostatic hyperplasia (BPH), a non-malignant but potentially severe enlargement of the surrounding prostatic cells. ${ }^{[16,17]}$ Hence, any potential cytotoxic effects of gene therapy on neighboring cells and tissues can be beneficial and not prohibitive to the treatment. ${ }^{[18-20]}$ Additionally, making use of cell surface biomarker proteins that are specifically overexpressed in PC, gene therapy potentially can be targeted to metastasized PC cells through systemic administration, using a targeted approach. ${ }^{[21-23]}$

The major deterrent in clinical translation of this approach is the lack of effective delivery systems for therapeutic nucleic acids (NAs) to target cells. ${ }^{[24]}$ Currently, virus-based delivery systems are at the forefront of research for clinical applications due to high transfection efficiency. ${ }^{[25]}$ However, viral vectors continue to be plagued with significant issues of non-desirable side effects like toxicity, non- 
targeted insertions and insufficient long-term clinical studies. ${ }^{[26,27]}$ Alternative non-viral delivery systems can be designed to counteract drawbacks of the viral system by being safer with reduced immunogenicity, possess more adaptable synthesis routes to carry larger genetic loads, and be comparatively cheaper to develop. ${ }^{[28]}$ The bottleneck in clinical translation exists due to restrictions imposed by the lack of suitable and sufficient research on their practical applications. ${ }^{[29]}$ Global regulatory bodies have approved only thirteen gene therapy delivery systems; ${ }^{[30]}$ all based on viruses because, up to 2018 , only $<0.25 \%$ of entire gene delivery-based research was reported on non-viral alternatives. ${ }^{[31]}$ It is thus critical to suitably address the lack of non-viral gene delivery systems, especially for a disease like PC that is suitable to gene therapy.

Nanoscale metal-organic-frameworks (MOFs) are porous materials that have recently been shown to be novel and effective non-viral systems for gene delivery. ${ }^{[32,33]}$ MOFs are built of metal ions anchored to organic bridging ligands by coordination bonds that result in two- or three - dimensional extended structures ${ }^{[34]}$. They can be synthesized to be biocompatible and biodegradable with excellent loading capacity and desirable release profiles. ${ }^{[35-38]}$ We and others have previously demonstrated that zeolitic imidazolate framework-8 (ZIF-8) polymorphs are a MOF sub-type suitable for delivering intact, functional genes using a proof-of-concept plasmid gene. ${ }^{[33,39]}$ In this new study, we report the ability of the ZIF-8 polymorph ZIF-C to act as gene therapy delivery agents to human PC cells by specifically targeting the LAM67R that is dysregulated in PC. The LAM67R protein is coded in humans by ribosomal protein SA gene (RPSA, NCBI Gene ID: 3921, Accession No.: AC_000135). ${ }^{[40]}$ The overexpression of LAM67R plays a crucial role in cancer metastasis and angiogenesis; its downregulation is known to significantly reduce cancer cell viability and increase apoptosis. ${ }^{[41,42]}$ We demonstrate the potential of ZIF-C for RPSA suppression in PC cells by using the two most common approaches to alter gene expression - RNA interference (RNAi) and clustered regularly interspaced short palindromic repeats (CRISPR) mediated knockdown and gene editing. ${ }^{[43,44]}$ RNAi technology is a traditional and powerful transient gene suppression system that acts at the transcriptional (RNA) level. It consists of short NA chains of no more than 30 bases called small 
interfering RNAs (siRNAs) that cleave the target mRNA to cause knockdown. ${ }^{[4]}$ ZIF-8 polymorphs have previously been reported for siRNA delivery in breast, lung and ovarian cancer cells. ${ }^{[46]}$ Nevertheless, while RNAi predominates the field of gene expression knockdown for the past two decades, the CRISPR/Cas9 system, first reported in 2012, is overtaking all earlier gene editing platforms to provide the best balance for efficiency, targeting precision, versatility, flexibility and cost efficacy. ${ }^{[47-}$ ${ }^{50]}$ The CRISPR/Cas9 gene editing tool acts on the genetic (DNA) level and is available in three different formats i.e. protein, mRNA or plasmid DNA systems. ${ }^{[51]}$ ZIF-8 has recently been shown to successfully deliver CRISPR/Cas9 in Chinese Hamster Ovary (CHO) cells. However, only the protein form of CRISPR/Cas9, comprising a $160 \mathrm{kDa}$ ribo-nucleo protein and 170 nucleotide guide RNA sequence, was used for this ZIF-8 based delivery. ${ }^{[52]}$ The CRISPR/Cas9 plasmid systems range from 310 kilobase pairs $(\mathrm{kbp})$ in size and were previously considered too large for effective delivery using nanoscale MOF systems. However, ZIF-8 is reported to successfully encapsulate a $6.5 \mathrm{kbp}$ green fluorescent protein (GFP) plasmid while maintaining its genetic function. ${ }^{[33]}$ Here, we demonstrate the ability of ZIF-8 polymorph ZIF-C to deliver a $9.2 \mathrm{kbp}$ CRISPR/Cas9 plasmid form that is calculated to be $\sim 5980 \mathrm{kDa}$, based on the average molecular weight of DNA to be $650 \mathrm{Da} / \mathrm{bp} .{ }^{[53]}$ Our work shows the utilization of a CRISPR/Cas9 format that is $\sim 37$ times larger than previous reported systems for MOF based delivery. This is advantageous due to the low cost and stability of the plasmid system, as well as the potential for sustained Cas9 nuclease for continuous rather than transient gene editing. ${ }^{\text {[49] }}$ NA encapsulation was carried out based on the published methods of biomimetic mineralization. ${ }^{[54]}$ The utilization of water washing step during ZIF-8 polymorph synthesis is reported to be more suitable for cellular uptake. ${ }^{[33]}$ Powder XRD analysis revealed similarity to the recently reported ZIF-C polymorph of ZIF-8 ${ }^{[55]}$ and the synthesized particles were termed NA@ZIF-C. Two types of NA@ZIF-C biocomposites were synthesized - a short chain 19-nucleotide siRNAs targeted to RPSA mRNA (siRPSA@ZIF-C), and a complete $9.2 \mathrm{kbp}$ CRISPR/Cas9 plasmid gene construct targeted to RPSA in chromosomes (crRPSA@ZIF-C). To check if surface modification of the biocomposites would allow for enhanced specific targeting to PC cells, epigallocatechin gallate (EGCG), an FDA approved 
triphenolic phytochemical, from green tea was used. EGCG is a ligand for LAM67R with reported antioxidant and anticancer properties. ${ }^{[56,57]}$ Following synthesis, the NA@ZIF-C were incubated in an aqueous solution of EGCG to yield EGCG coated biocomposites (EsiRPSA@ZIF-C and EcrRPSA@ZIF-C).Cellular transfection studies in human bone-metastasized prostate cancer cells PC-3 with the four biocomposites (siRPSA@ZIF-C, EsiRPSA@ZIF-C, crRPSA@ZIF-C or EcrRPSA@ZIFC) were carried following the protocol from our previous published work. ${ }^{[58]}$ A significant $23 \pm 8 \%$ increase in cellular uptake was observed for EGCG coated biocomposites as compared to EGCG uncoated. Transcriptional efficiency of the ZIF-C based delivery system was determined by calculating the \%RPSA knockdown $(\% \mathrm{KD})$ of siRNA biocomposite treated cells using quantitative polymerase chain reactions (qPCR). A 22\%KD using siRPSA@ZIF-8 that significantly increased to almost 40\%KD using EsiRPSA@ZIF-C was observed. Genomic cleavage efficiency of the ZIF-C based system was determined by genomic cleavage detection $(\% \mathrm{GCD})$ of RPSA that was evaluated by running isolated chromosomal RPSA from CRISPR/Cas9 treated cells on a DNA gel electrophoresis. Using ZIF-C, we obtained RPSA genomic cleavage of $20 \%$, which showed slight increase to $25 \%$ on coating the particles with EGCG. Effect of RPSA knockdown using both siRNA or CRISPR/Cas9 increased cytotoxicity of the cancer cells with EGCG causing a reduction in cell viability.

In a typical experiment (Figure 1A), NAs (100 nM RPSA siRNAs or 0.49 pM RPSA CRISPR/Cas9 plasmid) were added to aqueous solutions of 2-methylimidazole (2mIM, $160 \mathrm{mM})$ followed by zinc acetate dihydrate $(40 \mathrm{mM})$ at room temperatures. Turbidity was generated in the clear solution within 10-15 seconds of adding precursors. The reaction was incubated for 10 minutes and then centrifuged at $10,000 \mathrm{rcf}$ for 20 minutes. The supernatant was discarded, and the pellet was washed with water to yield the NA@ZIF-8. The particles were termed siRPSA@ZIF-C or crRPSA@ZIF-C to denote siRNA or CRISPR/Cas9 plasmid NA@ZIF-C respectively. The resulting biocomposites were incubated in an aqueous solution of EGCG $(250 \mu \mathrm{M})$ at room temperature for 2 hours with shaking at $700 \mathrm{rpm}$. Following incubation, the biocomposites were collected and washed with water by centrifuging at 
10,000 rcf for 10 minutes three times to yield EGCG coated NA@ZIF-C, and termed EsiRPSA@ZIF-C orEcrRPSA@ZIF-C.

Scanning electron microscopy (SEM) was carried out on the siRPSA@ZIF-C, EsiRPSA@ZIF-C, crRPSA@ZIF-C or EcrRPSA@ZIF-C biocomposites (Figure 1B-E).siRPSA@ZIF-C (Figure 1B) and crRPSA@ZIF-C (Figure 1C)were similar to the aggregated plate-like morphology that has been reported for ZIF-C with a heterogeneous size distribution. ${ }^{[55]}$ However, EsiRPSA@ZIF-C (Figure 1D) and EcrRPSA@ZIF-C (Figure 1E) showed a shift to a more rounded morphology with a reduction in particle size as inferred from SEM images. This indicated a possible etching effect of the polyphenol EGCG on the NA@ZIF-C biocomposites.
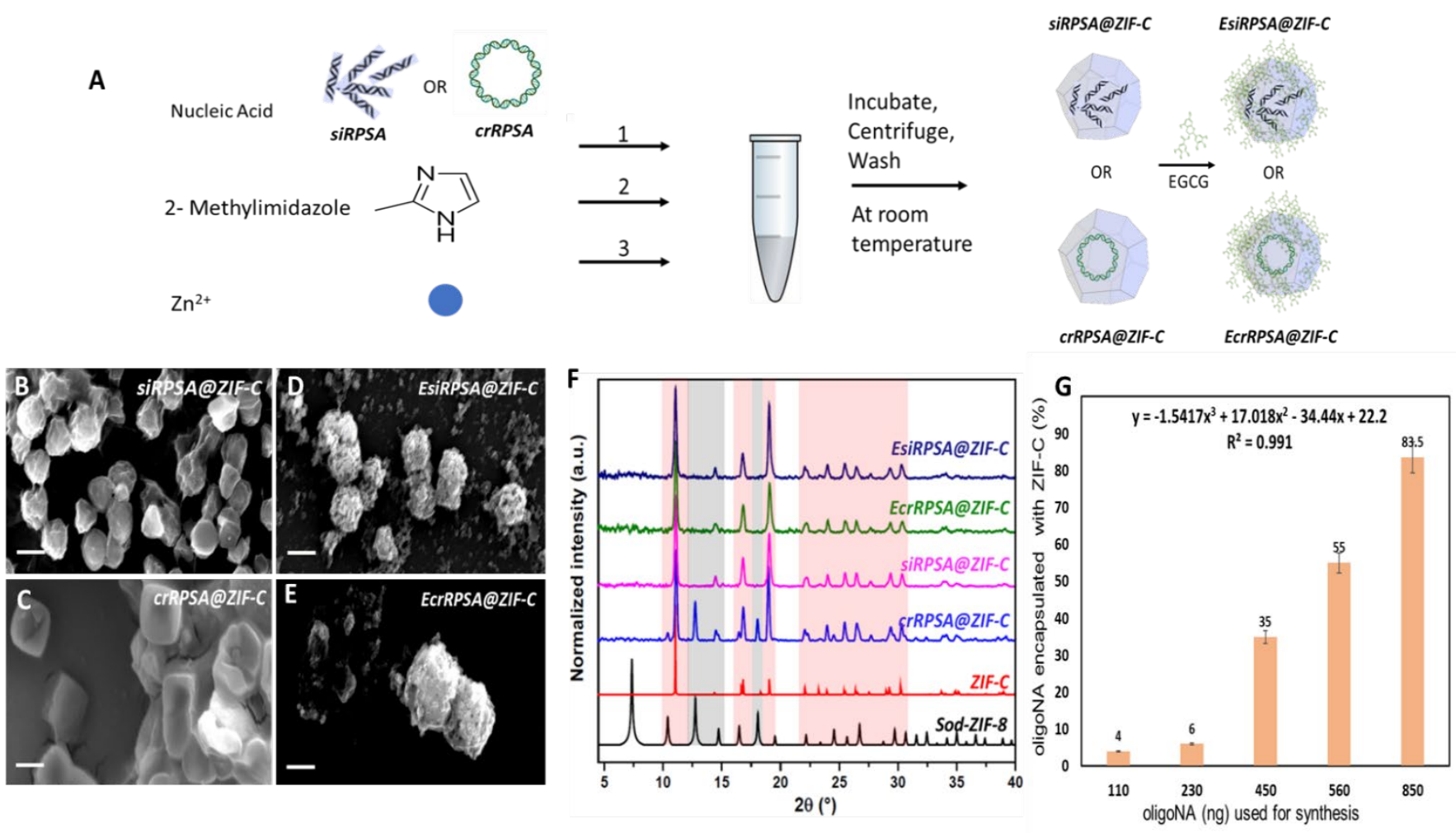

X ray diffraction patterns of the siRPSA@ZIF-C,EsiRPSA@ZIF-C, crRPSA@ZIF-C or

Figure 1. Synthesis and characterisation of NA@ZIF-C. (A) Schematic of synthesis of crRPSA@ZIF-C, siRPSA@ZIF-C,EcrRPSA@ZIF-C, or EsiRPSA@ZIF-C. (B-E) Scanning electron microscopy image of (B) siRPSA@ZIF-C, (C) crRPSA@ZIF-C, (D) EsiRPSA@ZIF-C and (E) EcrRPSA@ZIF-C, scale bars 200nm (B, C), 100 nm (D, E). (F) Powder X Ray Diffraction (PXRD) patterns of NA@ZIF-C biocomposites compared to ZIF-C, sod ZIF-8 polymorphs. (G) Fluorescence spectroscopy to determine loading efficiency of siRNA@ZIF-C using fluorescently labelled oligoNA.

EcrRPSA@ZIF-C biocomposites (Figure 1F) were compared to the simulated diffraction patterns of 
sodalite ZIF-8 (sod) [10.1021/ar900116g] and ZIF-C. ${ }^{[55]}$ The diffraction patterns indicate that the biocomposites possess ZIF-C topology, a dense ZIF phase recently obtained when proteins are added to HmIM and $\mathrm{Zn}^{2+}$ in water. ${ }^{[55]}$ Only in the case of crRPSA@ZIF-C we observed the presence of traces of sodalite. The $\mathrm{wt} \%$ ratio $\mathrm{ZIF}-\mathrm{C} / \mathrm{sod}=95 \% / 5 \%$ (Table $\mathrm{S} 1$ ) was quantified by the "ZIF phase analysis" [10.26434/chemrxiv.10059935] using the (220) peak at $12.75^{\circ}$.

DNA loading efficiency (percentage of DNA encapsulated) for biomimetically mineralized plasmid DNA was previously reported to be $82 \% .^{[33]}$ To calculate loading efficiency of the short chain NA in siRNA@ZIF-C, a fluorescent TAMRA (excitation/emission 565/580nm) labelled 19-mer oligonucleotide was used (Figure 1G). Following synthesis and encapsulation of the fluorescent NA, the biocomposites were degraded in $20 \mathrm{mM}$ EDTA solution to release oligonucleotide. Fluorescence spectroscopy was used to record the fluorescence emission intensity of the released NA. A standard curve of the labelled NA (Figure S2) was used to quantify amount from emission intensity. Around $\sim 80 \%$ of the short chain oligomer used for synthesis (850ng) was found to be present with the ZIF-C biocomposites.

To evaluate cellular uptake and delivery, the TAMRA labelled fluorescent oligomer was used for the NA@ZIF-C synthesis and EGCG coating. Transfection assays using both uncoated and EGCG coated biocomposites were carried out on PC-3 cells (Figure 2A-D). The cells were fixed and stained with Hoechst 3342 nuclear stain at 96 hours post transfection. Cell images were taken using confocal laser scanning microscope (CLSM) reveal that no red fluorescence could be detected in the untreated control cells (Figure 2A) but NA@ZIF-C treated cells showed fluorescence. A significant increase in fluorescence can be seen in EGCG coated treatment (Figure 2C) as compared to EGCG uncoated treatment (Figure 2B). EGCG coating at 96 hours (Figure 2C) showed transfection efficiency similar to that of routinely used Lipofectamine 3000 transfection reagent at 24 hours (Figure 2D). The relatively low fluorescence detected from the biocomposite treatment as compared to Lipofectamine 3000 is in line with the gradual release of NA proposed in earlier works of gene delivery using ZIF-8 
polymorph. ${ }^{[33]}$ However, the clear increase in fluorescence with the presence of EGCG indicates an enhanced cellular delivery of the MOF biocomposites due to the phytochemical.
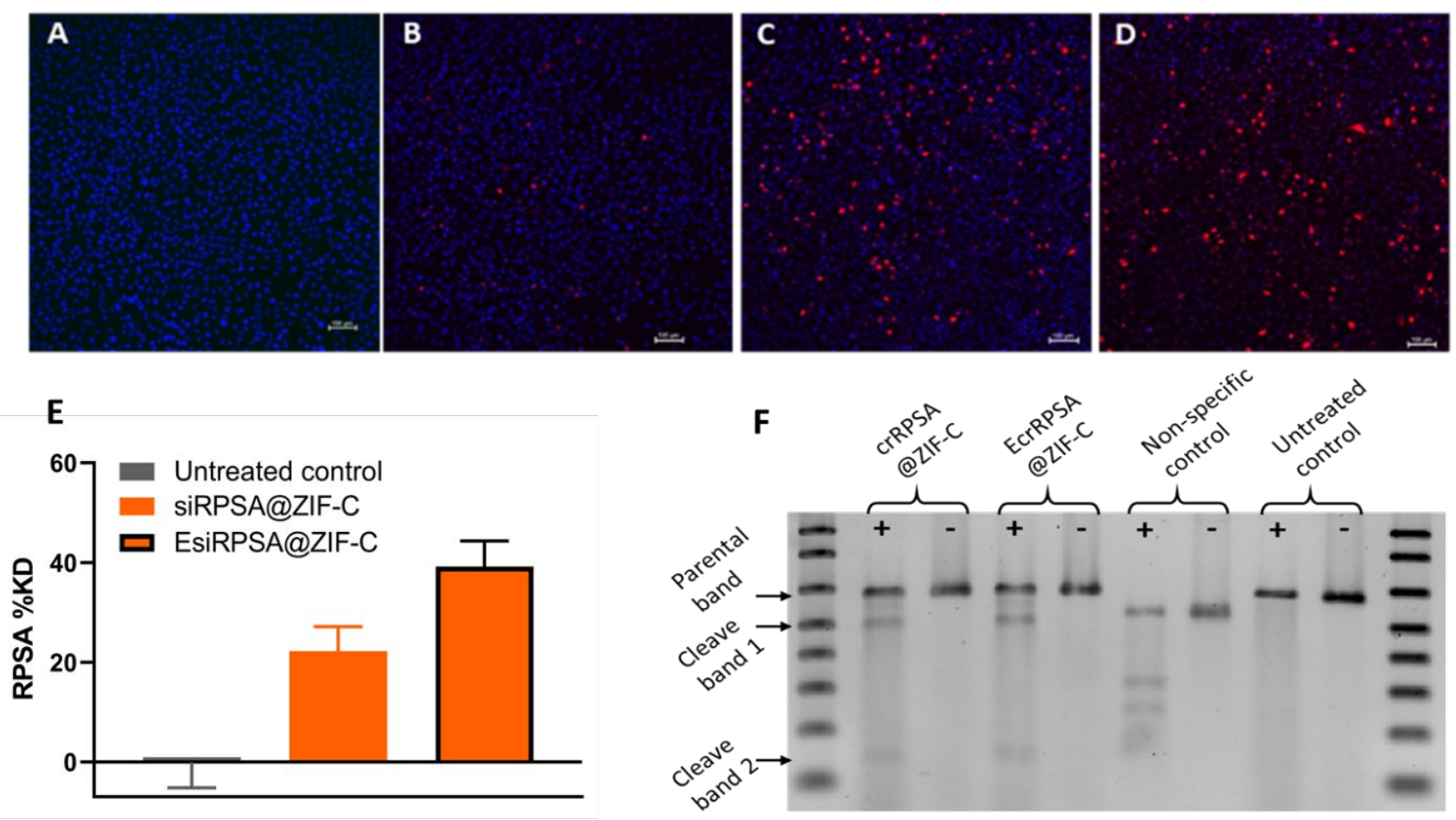

Figure 2. Cellular delivery and efficiency of siRNA and CRISPR/Cas9 using ZIF-C. (A-D) Confocal laser scanning microscope (CLSM) images of (A) Untreated PC-3 cells. (B) PC-3 cells transfected with TAMRA labelled oligoNA@ZIF-C at 96 hours, (C) PC-3 cells transfected with EGCG coated TAMRA labelled oligoNA@ZIF-C at 96 hours, and (D) PC-3 cells transfected with TAMRA labelled oligoNA@Lipofectamine ${ }^{\mathrm{TM}} 3000$ at 24 hours. Blue - cell population as seen by Hoechst 33342 nuclear stain. Red - fluorescence due to TAMRA label, scale bar 100 $\mu \mathrm{m}$. (E) Efficiency of RNAi using siRPSA biocomposites. RPSA mRNA knockdown of expression (\%KD) determined from qPCR results. (F) Efficiency of CRISPR/Cas9 using crRPSA biocomposites. RPSA genomic cleavage detection (\%GCD) determined from agarose gel electrophoresis.

Cellular delivery of CRISPR/Cas9 using ZIF-C was also evaluated. The CRISPR/Cas9 construct is a 9.2 kbp plasmid that has gene sequences coding for the Cas9 nuclease enzyme for cleaving the target RPSA gene, sequences for the short guide RNA sequence specific to RPSA for target specificity of the nuclease, and also sequences that code for an orange fluorescent protein (OFP) (Figure S1). While the plasmid itself is not fluorescent, its cellular internalization, transcription and translation is detected by 
generation of the OFP. Transfection assays were carried out using crRPSA@ZIF-C or EcrRPSA@ZIF-

C (Figure S3). Images were recorded at 96 hours post transfection when OFP began to be detected.

Similar to treatment with the short chain TAMRA-labelled NA@ZIF-C (Figure 2C), a gradual

fluorescence was observed in crRPSA@ZIF-C treated cells that increased on treatment with

EcrRPSA@ZIF-C (Figure S3); further supporting that presence of EGCG led to enhanced cellular

delivery. Expression was gradual as fluorescence at 96 hours showed transfection efficiency similar to

that of routinely used Lipofectamine 3000 transfection reagent at 24 hours.

In order to evaluate the efficiency of RNAi activity on RPSA in PC-3 cells with ZIF-C based delivery of target siRNAs, RPSA \%KD was calculated (Figure 2E). Cells were treated with siRPSA@ZIF-C and EsiRPSA@ZIF-C.At 96 hours post treatment, the cells were harvested and total RNA from the cells were isolated. The mRNAs were converted to cDNA strands for running on qPCR with RPSA specific primers. The cycle threshold (CT) values obtained from qPCR were normalized to controls using the delta-delta-CT method to calculate the $\% \mathrm{KD}$ of RPSA. ${ }^{[59]}$ The results obtained show a marked increase in $\% \mathrm{KD}$ when EGCG coating is present; with $22 \% \mathrm{KD}$ from siRPSA@ZIF-C and 40\%KD from EsiRPSA@ZIF-C.

For evaluating the chromosomal gene editing of CRISPR/Cas9 when delivered using the ZIF-C biocomposites, RPSA \%GCD was calculated (Figure 2F). PC-3 cells were treated with crRPSA@ZIFC or EcrRPSA@ZIF-C.At 96 hours post treatment, the cells were harvested and genomic DNA from the cells were isolated. The chromosomal region of the RPSA gene was amplified using standard polymerase chain reactions (PCR) with RPSA specific primers (Table S2 and Figure S4). The amplified strands were denatured and reannealed because cleavage by CRISPR/Cas9 results in a mismatch in the target DNA strand, and this mismatch can be detected by a mismatch detection enzyme in the reannealed strands. To visualize the effect of the detection enzyme on DNA, the enzyme reaction products were run on a $2 \%$ agarose gel electrophoresis with $(+)$ and without $(-)$ the detection enzyme treatment. With CRISPR/Cas9 cleavage of the target, two cleavage bands are formed on treatment with the detection enzyme. Hence, successful gene editing is indicated by the presence of a parental band 
which is the uncleaved part of the target gene, and two cleavage bands that result from the Cas9 nuclease activity. Where the detection enzyme is absent, only the parental band can be seen (Figure $2 \mathrm{~F}$ '-'lanes), and where it is present, parental as well as cleavage bands can be seen (Figure 2F '+' lanes). In untreated control cells, no cleavage bands are present in both '+ and -' lanes as no editing of the target RPSA has occurred. In crRPSA@ZIF-C or EcrRPSA@ZIF-C lanes (+), cleavage bands are distinctly visible. A non-specific control cleavage strand for the detection enzyme is used in gel densitometry analysis to calculate the percentage genomic cleavage (\%GCD) carried out by the CRISPR/Cas9 system. The presence of cleavage bands on treatment with crRPSA@ZIF-C or EcrRPSA@ZIF-C thus clearly indicates gene editing carried out by the MOF assisted CRISPR/Cas9 delivery. The effect of both siRNA and CRISPR mediated disruption on RPSA using ZIF-C was compared by checking for RPSA gene expression following the disruption (Figure 3A). qPCR was carried out to check for RPSA expression levels after siRPSA or crRPSA treatments. The CT values obtained for RPSA were normalized to untreated cells. As compared to untreated, RPSA knock down was more pronounced in case of cytoplasmic RNAi than genomic CRISPR/Cas9. The CRISPR/Cas9 system works by causing a single mutation, known as indel, in the genomic sequence of RPSA. The mutated gene is then unable to be transcribed into a correct RPSA mRNA, the correct form of which is ultimately responsible for producing the LAM67R protein. Although CRISPR/Cas9 sufficiently reduced gene expression, as can be seen from the results (Figure 3A, green), a greater reduction in the expression is obtained with siRNAs (Figure 3A, orange). The RNAi system works by targeting the correct RPSA mRNA itself, at cytoplasmic level downstream to the nuclear pathway where CRISPR/Cas9 acts. Thus, it is postulated that higher interruptions of LAM67R protein expression can be achieved by aiming for pathways downstream to the chromosomal genetic level. Reduction in expression also increased in the presence of EGCG. This effect is possibly due to the increased uptake of EGCG coated particles in accordance with the cellular uptake and transfection results. ${ }^{[56]}$ 
Interestingly, cellular toxicity increased when RPSA was targeted by the CRISPR/Cas9 system rather than the RNAi system (Figure 3B). The impact of RPSA knockdown using both the siRNA and CRISPR/Cas9 systems on cellular viability was evaluated using MTT viability assays. The non-specific NA@ZIF-C using non-targeting oligomer NA or green fluorescent protein (GFP) plasmid were used as controls to assess the toxicity of ZIF-C polymorphs as gene delivery systems. These controls confirmed the non-toxicity of the delivery system itself as cells retained more than $85 \%$ viability at 72 and 96 hours post treatment (Figure S5). The results show that viability steadily decreased from $72 \%$ at 24 hours post treatment to $34 \%$ at 96 hours post treatment with crRPSA@ZIF-C. Moreover, when EGCG
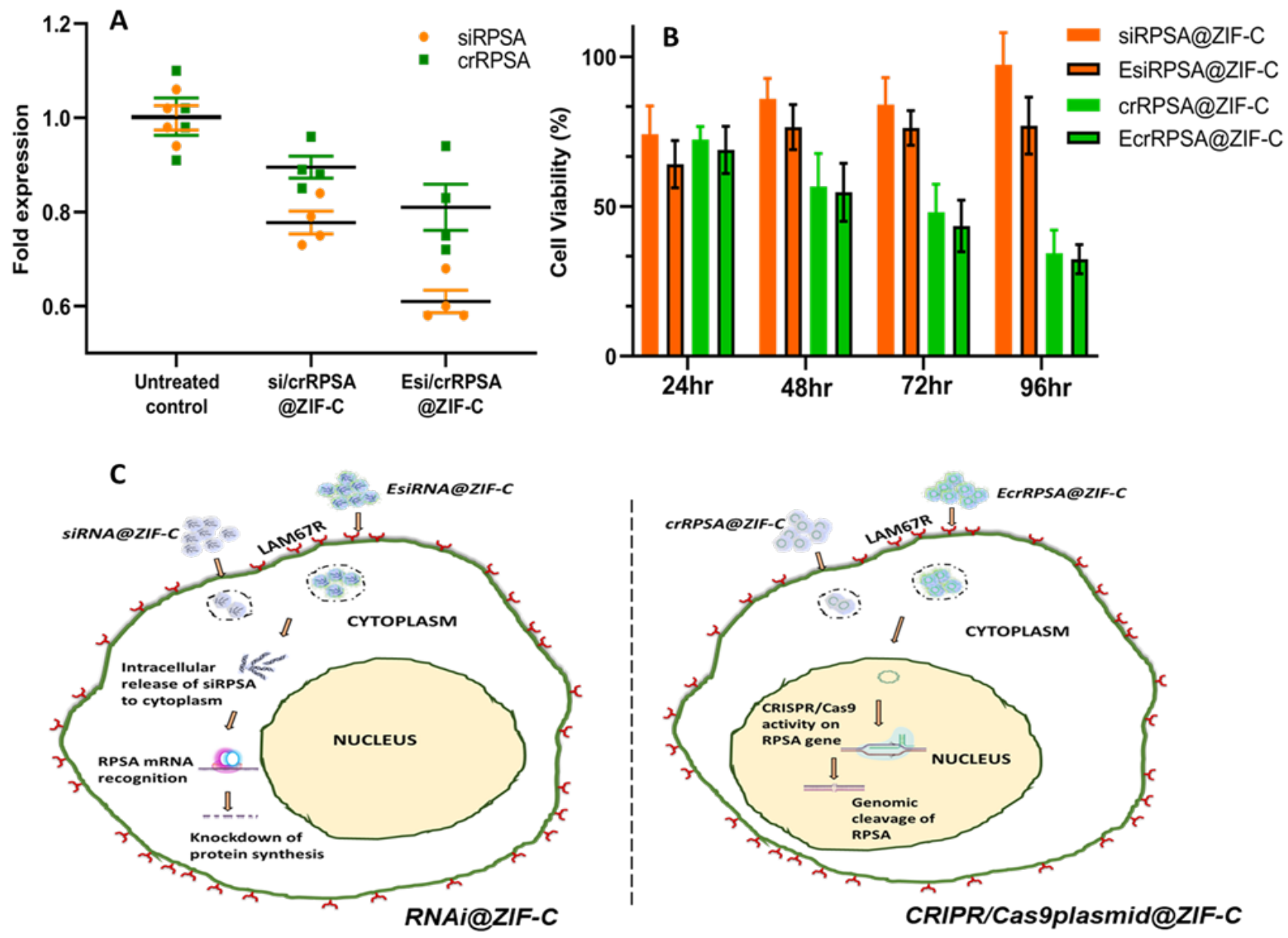

Figure 3. Effect on RPSA KD using ZIF-C delivered RNAi and CRISPR/Cas9. (A) RPSA fold expression as calculated from qPCR. Replicate data points shown. (B) Cellular viability of PC-3 cells after 3.5 hour treatment with NA@ZIF-C biocomposites at 24, 48, 72 delivery and 96 hours. (C) Schematic of proposed gene knock down mechanism at cytoplasmic level on of RNAi@ZIF-C (left) versus chromosomal level on delivery of CRISPR/Cas9plasmid@ZIF-C (right). 
coating was added to the biocomposites, a consistent increase in cytotoxicity pattern was further detected. The decrease in viability with EGCG occurs in both the control and experimental biocomposites, which is in accordance to reports of EGCG itself having a possible cytotoxic effect on cancer cells. However, as clearly indicated from transfection studies, EGCG also has a concomitant effect on enhancing cellular delivery of the NA@ZIF-C biocomposites. Thus, the affinity between EGCG and LAM67R, protein product of RPSA, causes increased uptake of the polyphenol coated particles. This in turn delivers the RPSA gene editing NAs, and the disruption of RPSA leads to an added increase in PC-3 toxicity (Figure 3C).

In conclusion, we demonstrate the ability of the ZIF-8 polymorph ZIF-C to act as a suitable gene therapy delivery system for prostate cancer. Specifically, ZIF-C based encapsulation of not just short chain siRNAs, but the CRISPR/Cas9 system in plasmid format is also utilized with successful editing of the genome. For treatment in PC cell line, coating with the green tea compound EGCG enhanced cellular uptake and reduced cell viability. The RPSA gene, which is overexpressed in PC, was specifically targeted by the ZIF-C based delivery systems, which caused significant increase in toxicity following disruption of the gene. Thus, we show that nanoscale MOFs like ZIF-C are highly promising not only for gene therapy of PC, but in a wider application of the CRISPR tool in its plasmid format. While the significance of ZIF-C as a potential gene delivery agent is thus revealed, the biological relevance and sufficiency warrants further investigation. Conceptually, a single copy of a gene in a single cell is enough to synthesize the encoded proteins. However, verifying how many copies of a target gene are required per cell in order to produce systemically sufficient results remains a 'holy grail' of molecular biology and genetics. Further studies examining gene copies or number of nucleic acid molecules associated with each ZIF-C like MOF particles are needed for elucidation of this genetic effectiveness and the material-biomolecule interface. As is evident from this work, the presence of EGCG increased uptake of ZIF-C in PC but the payoff is in reduced viability. Exploring the underlying causes are essential for deeper understanding in order to achieve customizable application dependent results; and investigation of these outcomes form the basis of future studies. 


\section{AUTHOR INFORMATION}

\section{Corresponding Author}

* Ravi Shukla. E-mail: ravi.shukla@rmit.edu.au. Phone: +61 3992529070. Fax: +61 399253747 (R.S.).

\section{ACKNOWLEDGMENT}

A.P. acknowledges the joint RMIT-CSIRO PhD scholarship support and funding provided by Australian Nanotechnology Network through their Overseas Travel Fellowship scheme. Dr Mugdha Joglekar, NHMRC-CTC, University of Sydney, is acknowledged for help with qPCR data analysis. R.S. acknowledges the support of Ian Potter Foundation in establishing Sir Ian Potter NanoBioSensing Facility. RMIT Micro Nano Research (MNRF) and Microscopy \& Microanalysis (RMMF; a linked laboratory of the Microscopy Australia) facilities are acknowledged for technical assistance and access to equipment. P.F. and F.C. acknowledge LP-03. A. R. acknowledges financial support from ANAT in the form of a synapse science art residency.

\section{REFERENCES}

[1] Rawla P. World Journal of Oncology 2019, 10:63-89.

[2] Bray F, Ferlay J, Soerjomataram I, Siegel RL, Torre LA, Jemal A. CA Cancer J Clin 2018, 68:394424.

[3] Jayadevappa R, Chhatre S, Wong Y-N, Wittink MN, Cook R, Morales KH, Vapiwala N, Newman DK, Guzzo T, Wein AJ, Malkowicz SB, Lee DI, Schwartz JS, Gallo JJ. Medicine 2017, 96:e6790e6790.

[4] Sumanasuriya S, De Bono J. Cold Spring Harb Perspect Med 2018, 8.

[5] Teo MY, Rathkopf DE, Kantoff P. Annual Review of Medicine 2019, 70:479-499.

[6] Litwin MS, Tan HJ. Jama 2017, 317:2532-2542.

[7] Thurtle D, Rossi SH, Berry B, Pharoah P, Gnanapragasam VJ. BMJ Open 2019, 9:e029149.

[8] Anguela XM, High KA. Annual Review of Medicine 2019, 70:273-288.

[9] Jones D, Friend C, Dreher A, Allgar V, Macleod U. BMC family practice 2018, 19:79-79. 
[10] Mitterberger M, Horninger W, Aigner F, Pinggera GM, Steppan I, Rehder P, Frauscher F. Cancer imaging : the official publication of the International Cancer Imaging Society 2010, 10:40-48.

[11] Ludwig DR, Fraum TJ, Fowler KJ, Ippolito JE. Missouri medicine 2018, 115:135-141.

[12] Amaro A, Esposito AI, Gallina A, Nees M, Angelini G, Albini A, Pfeffer U. Cancer and Metastasis Reviews 2014, 33:657-671.

[13] Shen MM, Abate-Shen C. Genes \& development 2010, 24:1967-2000.

[14] Wang G, Zhao D, Spring DJ, DePinho RA. Genes \& development 2018, 32:1105-1140.

[15] Gandhi J, Afridi A, Vatsia S, Joshi G, Joshi G, Kaplan SA, Smith NL, Khan SA. Prostate Cancer Prostatic Dis 2018, 21:22-36.

[16] Ørsted DD, Bojesen SE. Nature Reviews Urology 2013, 10:49-54.

[17] Dai X, Fang X, Ma Y, Xianyu J. Medicine 2016, 95:e3493-e3493.

[18] Altwaijry N, Somani S, Dufès C. International Journal of Nanomedicine 2018, 13:5753-5767.

[19] Karantanos T, Corn PG, Thompson TC. Oncogene 2013, 32:5501-5511.

[20] Ahmed KA, Davis BJ, Wilson TM, Wiseman GA, Federspiel MJ, Morris JC. Frontiers in Oncology 2012, 2:172-172.

[21] Shukla R, Chanda N, Zambre A, Upendran A, Katti K, Kulkarni RR, Nune SK, Casteel SW, Smith CJ, Vimal J, Boote E, Robertson JD, Kan P, Engelbrecht H, Watkinson LD, Carmack TL, Lever JR, Cutler CS, Caldwell C, Kannan R, Katti KV. Proceedings of the National Academy of Sciences of the United States of America 2012, 109:12426-12431.

[22] Zhou M, Chinnaiyan AM, Kleer CG, Lucas PC, Rubin MA. The American Journal of Surgical Pathology 2002, 26:926-931.

[23] Weng J, Wang J, Hu X, Wang F, Ittmann M, Liu M. International Journal of Cancer 2006, 118:1471-1480.

[24] Sung YK, Kim SW. Biomaterials Research 2019, 23:8.

[25] Lundstrom K. Diseases (Basel, Switzerland) 2018, 6:42.

[26] Yang N. International Journal of Pharmaceutical Investigation 2015, 5:179-181. 
[27] Marguillier L, Dubruel P, Van Vlierberghe S. Gene Therapy Approaches Toward Biomedical Breakthroughs. In: Van Hoorick J, Ottevaere H, Thienpont H, Dubruel P, Van Vlierberghe S, eds. Polymer and Photonic Materials Towards Biomedical Breakthroughs. Cham: Springer International Publishing; 2018, 153-176.

[28] Chira S, Jackson CS, Oprea I, Ozturk F, Pepper MS, Diaconu I, Braicu C, Raduly L-Z, Calin GA, Berindan-Neagoe I. Oncotarget 2015, 6:30675-30703.

[29] A A. Gene Delivery. In: Subramanian G, ed. Manufacturing of Gene Therapeutics: Springer, Boston, MA; 2002, 245-272.

[30] Shukla V, Seoane-Vazquez E, Fawaz S, Brown L, Rodriguez-Monguio R. Human Gene Therapy Clinical Development 2019, 30:102-113.

[31] Hidai C, Kitano H. Diseases (Basel, Switzerland) 2018, 6:57.

[32] Wang H, Chen Y, Wang H, Liu X, Zhou X, Wang F. Angewandte Chemie International Edition 2019, 58:7380-7384.

[33] Poddar A, Conesa JJ, Liang K, Dhakal S, Reineck P, Bryant G, Pereiro E, Ricco R, Amenitsch H, Doonan C, Mulet X, Doherty CM, Falcaro P, Shukla R. Small 2019, 15:1970193.

[34] Zhou H-C, Long JR, Yaghi OM. Chemical Reviews 2012, 112:673-674.

[35] Doonan C, Riccò R, Liang K, Bradshaw D, Falcaro P. Accounts of Chemical Research 2017, 50:1423-1432.

[36] McKinlay AC, Morris RE, Horcajada P, Férey G, Gref R, Couvreur P, Serre C. Angewandte Chemie International Edition 2010, 49:6260-6266.

[37] Cai H, Huang Y-L, Li D. Coordination Chemistry Reviews 2019, 378:207-221.

[38] Wuttke S, Braig S, Preiß T, Zimpel A, Sicklinger J, Bellomo C, Rädler JO, Vollmar AM, Bein T. Chemical Communications 2015, 51:15752-15755.

[39] Li Y, Zhang K, Liu P, Chen M, Zhong Y, Ye Q, Wei MQ, Zhao H, Tang Z. Advanced Materials 2019, 31:1901570. 
[40] DiGiacomo V, Meruelo D. Biological reviews of the Cambridge Philosophical Society 2016, 91:288-310.

[41] Moodley K, Weiss SFT. PloS one 2013, 8:e57409-e57409.

[42] Scheiman J, Tseng J-C, Zheng Y, Meruelo D. Molecular therapy : the journal of the American Society of Gene Therapy 2010, 18:63-74.

[43] Smith I, Greenside PG, Natoli T, Lahr DL, Wadden D, Tirosh I, Narayan R, Root DE, Golub TR, Subramanian A, Doench JG. PLOS Biology 2017, 15:e2003213.

[44] Unniyampurath U, Pilankatta R, Krishnan MN. International journal of molecular sciences 2016, $17: 291-291$.

[45] Kim D, Rossi J. BioTechniques 2008, 44:613-616.

[46] Pan Q-S, Chen T-T, Nie C-P, Yi J-T, Liu C, Hu Y-L, Chu X. ACS Applied Materials \& Interfaces 2018, 10:33070-33077.

[47] Jinek M, Chylinski K, Fonfara I, Hauer M, Doudna JA, Charpentier E. Science 2012, 337:816821.

[48] Cho SW, Kim S, Kim JM, Kim JS. Nature Biotechnology 2013, 31:230-232.

[49] Lino CA, Harper JC, Carney JP, Timlin JA. Drug Delivery 2018, 25:1234-1257.

[50] Pickar-Oliver A, Gersbach CA. Nature Reviews Molecular Cell Biology 2019, 20:490-507.

[51] Eoh J, Gu L. Biomaterials Science 2019, 7:1240-1261.

[52] Alsaiari SK, Patil S, Alyami M, Alamoudi KO, Aleisa FA, Merzaban JS, Li M, Khashab NM. Journal of the American Chemical Society 2018, 140:143-146.

[53] Mathew-Fenn RS, Das R, Silverman JA, Walker PA, Harbury PAB. PloS One 2008, 3:e3229e3229.

[54] Liang K, Ricco R, Doherty CM, Styles MJ, Bell S, Kirby N, Mudie S, Haylock D, Hill AJ, Doonan CJ, Falcaro P. Nature Communications 2015, 6:7240. 
[55] Carraro F, Velasquez M, Astria E, Liang W, Twight 1, parise c, ge m, Huang Z, Ricco R, Zou X, villanova 1, Kappe O, Doonan C, falcaro p. 2019. Available at:

http://europepmc.org/abstract/PPR/PPR101188 https://doi.org/10.26434/chemrxiv.10059935.v1.

[56] Nune SK, Chanda N, Shukla R, Katti K, Kulkarni RR, Thilakavathi S, Mekapothula S, Kannan R, Katti KV. Journal of Materials Chemistry 2009, 19:2912-2920.

[57] Yang CS, Wang X, Lu G, Picinich SC. Nature Reviews Cancer 2009, 9:429-439.

[58] Poddar A, Conesa JJ, Liang K, Dhakal S, Reineck P, Bryant G, Pereiro E, Ricco R, Amenitsch H, Doonan C, Mulet X, Doherty CM, Falcaro P, Shukla R. Small 2019, 15:1902268.

[59] Hardikar AA, Farr RJ, Joglekar MV. Journal of the American Heart Association 2014, 3:e000792. 
Supporting Information

\section{ZIF polymorphs for Nucleic Acid Delivery and Targeted Knockdown of Gene Expression in Prostate Cancer}

Arpita Poddar, ${ }^{\dagger \S}$ Suneela Pyreddy, ${ }^{\dagger}$ Francesco Carraro, ${ }^{\#}$ Sudip Dhakal, ${ }^{\dagger}$ Andrea Rassell, ${ }^{\dagger}$ Matthew $R$. Field, "T. Srinivasa Reddy, ${ }^{\dagger}$ Paolo Falcaro, ${ }^{\#}$ Cara M. Doherty, ${ }^{\S}$ Ravi Shukla ${ }^{\dagger}$

$\dagger$ Ian Potter NanoBiosensing Facility, NanoBiotechnology Research Laboratory (NBRL), School of Science, RMIT University, Melbourne, Victoria 3001, Australia

I RMIT Microscopy \& Microanalysis Facility, RMIT University, Melbourne, Victoria 3001, Australia \# Institute of Physical and Theoretical Chemistry, Graz University of Technology, 8010 Graz, Austria $\S$ CSIRO Manufacturing, Clayton, Victoria 3168, Australia

Materials

Zinc acetate dihydrate, 2-Methylimidazole (2mIM) and ethylenediaminetetraacetic acid disodium salt dihydrate were obtained from Sigma-Aldrich. Lipofectamine ${ }^{\mathrm{TM}} 3000$ Transfection Reagent, GeneArt ${ }^{\circledR}$ CRISPR Nuclease (OFP Reporter) Vector Kit with Competent Cells, PureLink ${ }^{\mathrm{TM}}$ HiPure Plasmid DNA Purification Kits and GeneArt ${ }^{\circ}$ Genomic Cleavage Detection Kits were purchased from Life technologies. siGENOME Human RPSA (3921) siRNA - SMARTpool was purchased from Dharmacon. RPMI media, Opti-MEM and MTT (3-(4,5-Dimethylthiazol-2-yl)-2,5Diphenyltetrazolium Bromide) from Life technologies. All other reagents were obtained from SigmaAldrich and used without further modification.

Methods

RNAi for targeting human RPSA gene (NCBI Gene ID: 3921)

SMARTpool siRNA, M-013303-01-0005 siGENOME, that contained a mixture of 4 sequences targeting RPSA RNA was purchased from Dharmacon. The sequences are as follows: 
1. D-013303-01: GGUCAUGCCUGAUCUGUAC

2. D-013303-02: GCACCAAUCUUGACUUCCA

3. D-013303-03: GCGCAUGCGUGGCACCAUU

4. D-013303-04: CAACAAGGGAGCUCACUCA

The SMARTpool siRNA was resuspended following manufactures' protocol (Dharmacon ${ }^{\mathrm{TM}}$ siRNA Resuspension) into $20 \mu \mathrm{M}$ stock solution which was subsequently termed as siRPSA.

CRISPR/Cas9 plasmid for targeting human RPSA gene (NCBI Gene ID: 3921)

The gRNA sequences to target RPSA gene were designed using the CRISPR guide-RNA (gRNA) in silico tool 'GeneArt CRISPR Search and Design Tool' from Invitrogen TrueDesign Genome Editor software. The single stranded oligo DNA sequences for yielding the gRNAs are as follows:

1. RPSA-gRNA-R1 (fwd): CTATCCTGATACATACCAGTGTTTT RPSA-gRNA-R1 (rev): ACTGGTATGTATCAGGATAGCGGTG

2. RPSA-gRNA-R2 (fwd): CATAAGCAAATTGGACGACTGTTTT RPSA-gRNA-R2 (rev): AGTCGTCCAATTTGCTTATGCGGTG

3. RPSA-gRNA-R3 (fwd): TGCCTGGATCTGGTTAGTGAGTTTT RPSA-gRNA-R3 (rev): TCACTAACCAGATCCAGGCACGGTG

Double stranded oligos were generated by annealing the single stranded sequences following manufacturer's protocol (GeneArt® CRISPR Nuclease Vector Kit) and ligated to the CRISPR nuclease vector plasmid (Figure S1). The successfully ligated plasmid contained the following features to form a complete RPSA targeting CRISPR/Cas9 gene sequence in a single format:

1. Cas9 nuclease coding sequence.

2. Annealed oligonucleotides coding for the target gRNA sequences.

3. tracrRNA: Auxiliary trans-activating crRNA allows loading of Cas9 nuclease onto the gRNA

4. F1 origin of replication: Origin of replication.

5. TK pA: Polyadenylation signal. 
6. OFP: Reporter gene for orange fluorescent protein.

7. 2A peptide linker: A self-cleaving peptide linker connecting CD4 or OFP reporter genes to the C-terminal end of Cas9 nuclease. Following translation, the two proteins flanking the 2A peptide are separated from each other.

8. CMV promoter: Allows expression of Cas9 nuclease and OFP reporter genes.

9. Human U6 promoter: Allows RNA Polymerase III-dependent expression of the guide RNA (gRNA) (Kunkel et al., 1986; Kunkel and Pederson, 1988).

10. U6 forward priming site: Allows sequencing of the insert.

11. 3' overhangs: Allows ligase-mediated directional cloning of the double-stranded oligonucleotide of interest.

12. Pol III terminator: Allows efficient termination of RNA Polymerase III-dependent transcription.

13. Ampicillin resistance gene: Allows selection of the plasmid in E. coli.

14. pUC origin of replication (ori): Permits high-copy replication and maintenance in E. coli.

\begin{tabular}{|l|l|}
\hline RPSA specific gRNA oligo & Designed sequence \\
\hline RPSA-gRNA-R2 (fwd) & CATAAGCAAATTGGACGACTGTTTT \\
RPSA-gRNA-R2 (rev) & AGTCGTCCAATTTGCTTATGCGGTG \\
\hline
\end{tabular}

1. Single stranded sequences are annealed to give double stranded oligos (dso) specific to RPSA gRNA.

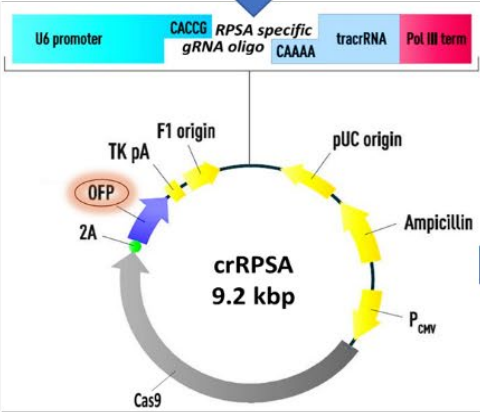

2. dso RPPSA gRNA are cloned into CRISPR/Cas9 plasmid.
5. Amplified plasmids are extracted from E.coli and confirmed for correct RPSA gRNA sequence.

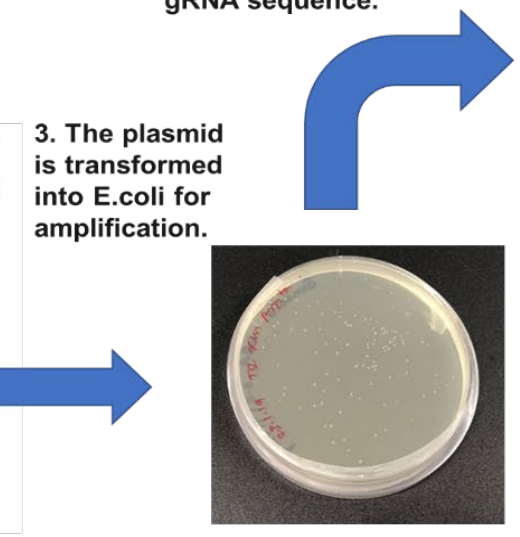

4. Colony formation occurs only in the case of successful cloning and transformation

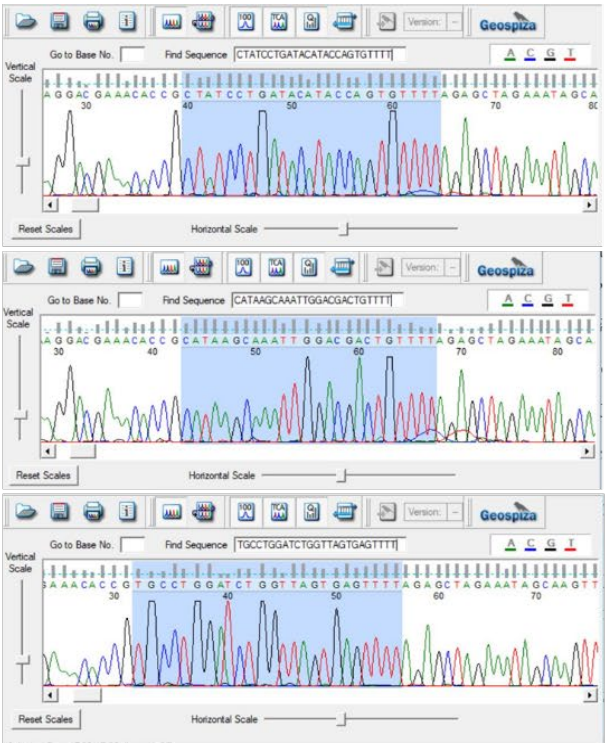

6. Once sequence verified, CRISPR/Cas9 plasmid is ready to use and can be stored and amplified indefinitely

Figure S1. Generation of CRISPR/Cas9 plasmid crRPSA.

Once the double stranded circular plasmid was constructed, the plasmid was amplified by transforming into One Shot ${ }^{\circledR}$ TOP10 chemically competent E. coli cells. The transformed cells were plated on LB 
plates containing $100 \mu \mathrm{g} / \mathrm{mL}$ ampicillin overnight at $37^{\circ} \mathrm{C}$ incubator. Growth of colonies indicated successful plasmid construction and ligation (Figure S1). 3-5 ampicillin resistant colonies were selected and inoculated in LB broth containing $100 \mu \mathrm{g} / \mathrm{mL}$ ampicillin and grown at $37^{\circ} \mathrm{C}$ with $200 \mathrm{rpm}$ overnight. The amplified plasmids were isolated using PureLink ${ }^{\mathrm{TM}}$ HiPure Plasmid Midiprep Kit. Sequencing reactions were carried out on the plasmid for final confirmation that the correct RPSA targeting gRNA sequence was constructed. Sequencing was performed at Micromon Genomics facility at Monash University, Australia and matched to the designed gRNA oligoDNA sequence (Figure S2A-C). The verified plasmid construct was termed as crRPSA and stored at stock concentrations of $0.5-3 \mu \mathrm{g} / \mu \mathrm{L}$. This single format CRISPR/Cas9 system (crRPSA) could now be stored, amplified and used indefinitely.

Biomimetic mineralization-based synthesis of siRPSA@ZIF-C and crRPSA@ZIF-C.

Aqueous solution of $160 \mathrm{mM}$ of $2 \mathrm{mIM}(13 \mathrm{mg} / \mathrm{mL})$ and $40 \mathrm{mM}$ of zinc acetate dihydrate $(8.9 \mathrm{mg} / \mathrm{mL})$ were made separately. In a $1.5 \mathrm{ml}$ tube, $100 \mathrm{~nm}$ siRPSA or 0.49 pmols crRPSA was mixed first with $2 \mathrm{mIM}(100 \mu \mathrm{L})$ and then zinc acetate dihydrate $(100 \mu \mathrm{L})$. The mixture slowly turned cloudy and was left at room temperature for 10 mins. The products were centrifuged at 10,000 rcf for 10 mins and washed in water three times.

Synthesis of EsiRPSA@ZIF-C and EcrRPSA@ZIF-C

Synthesized siRPSA@ZIF-C and crRPSA@ZIF-C were dispersed in 250 $\mu$ M of EGCG solution for 2 hours at $700 \mathrm{rpm}$. The product is then centrifuged at 10,000 $\mathrm{rcf}$ for $10 \mathrm{mins}$ and the pellet is washed in water three times followed by disperseal in $100 \mu \mathrm{L}$ of water for further use.

Scanning electron microscopy (SEM)

SEM was used to investigate the particle morphology using a Carl Zeiss Gemini Field Emission Scanning Electron Microscope (FESEM). Approximately $2 \mu \mathrm{L}$ of the synthesized (siRPSA@ZIF-C, crRPSA@ZIF-C, EsiRPSA@ZIF-C and EcrRPSA@ZIF-C) sample mixture was drop-cast on a silicon 
wafer, allowed to air dry and followed by sputter coating with 5-6 $\mathrm{nm}$ of iridium. Imaging was done under high resolution visualization at EHT $5.0 \mathrm{kV}$ with High Efficiency (HE-SE2) detector for collecting secondary electrons.

SEM was also used to visualize the presence of NA@ZIF-C on PC-3 cell surface following treatment with the MOF particles. A non-toxic and non-targeting pCDNA5frt-EplGFP-N1 (CAT) plasmid was used to synthesize the biocomposites.

Powdered X Ray Diffraction

Diffraction patterns were collected using a Bruker D8 Discover GADDS Diffractometer. The x ray diffraction beam monochromator was a $\mathrm{Cu}$ target $\mathrm{x}$ ray tube with $\mathrm{K} \alpha$ radius $1.544 \AA$, set to $40 \mathrm{kV}$ generator intesity and $40 \mathrm{~mA}$ generator current. The step size was $0.01^{\circ}$. All data were collected at room temperature. The simulated sod-ZIF-8 and ZIF-C patterns were obtained from Cambridge Structural Database (CSD) OFERUN and [10.26434/chemrxiv.10059935, 10.1021/ic5027174] respectively. ${ }^{[1,2]}$ Diffraction patterns were run on the web application ZIF phase analysis (https://rapps.tugraz.at/apps/porousbiotech/ZIFphaseanalysis/) and the results are shown in Table S1.

\begin{tabular}{|l|l|l|}
\hline Sample & sod & $\boldsymbol{Z I F - C}$ \\
\hline crRPSA@ZIF-C & $5 \%$ & $95 \%$ \\
\hline EcrRPSA@ZIF-C & - & $100 \%$ \\
\hline EsiRPSA@ZIF-C & - & $100 \%$ \\
\hline siRPSA@ZIF-C & - & $100 \%$ \\
\hline
\end{tabular}

Table S1. ZIF phase analysis of biocomposites

Fluorescence Spectroscopy

To determine loading efficiency of short chain nucleic acids (NAs), a DNA oligomer labelled with TAMRA fluorophore (excitation maxima at $561 \mathrm{~nm}$ and emission maxima at $583 \mathrm{~nm}$ ) was used.

Different concentrations of the oligomer $(110 \mathrm{ng} / \mu \mathrm{L}, 230 \mathrm{ng} / \mu \mathrm{L}, 450 \mathrm{ng} / \mu \mathrm{L}, 560 \mathrm{ng} / \mu \mathrm{L}$ and $850 \mathrm{ng} / \mu \mathrm{L})$ were prepared according to the biomimetic mineralisation protocol. Following synthesis, the particles were dissolved using EDTA $(20 \mathrm{mM})$ and the fluorescence intensity from the samples were recorded 
using a SpectraMax Paradigm Multi-Mode Microplate Reader. The concentration of associated DNA was calculated from the fluorescence intensity using the standard curve method determined using

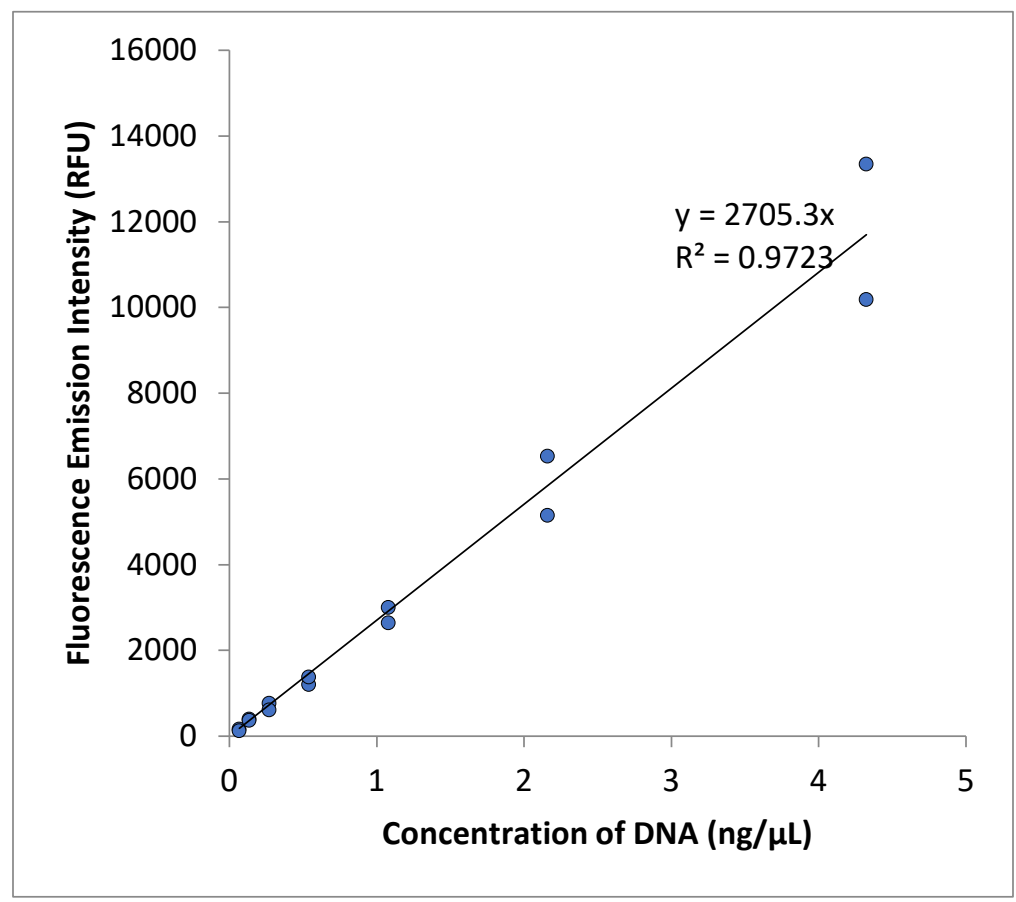

Figure S2. Standard curve for determination of oligoDNA concentration.

known concentrations of DNA dilutions. The standard curve (Figure S2) was obtained from a scatter diagram of concentration versus fluorescent emission intensity of the known DNA concentration diluted two-fold.

\section{Cell Transfection}

PC-3 prostate cancer cells were kindly provided by Prof John Mariadoson's lab in the Olivia NewtonJohn Cancer Research Centre. PC-3 cells were seeded in 6 well plate with the seeding density of $0.35 \times 106$ cells/well and incubated in RPMI medium supplemented with $4.5 \mathrm{~g} / \mathrm{L}$ D-glucose, $25 \mathrm{mM}$ Hepes, $0.11 \mathrm{~g} / \mathrm{L}$ sodium pyruvate, $1.5 \mathrm{~g} / \mathrm{L}$ sodium bicarbonate, $2 \mathrm{mML}$-glutamine $10 \% \mathrm{FBS}$ and $1 \%$ antibiotic at 37 $\mathrm{C}$ with 5\%CO2 overnight. Before transfection, siRPSA@ZIF-C, crRPSA@ZIF-C, EsiRPSA@ZIF-C or EcrRPSA@ZIF-C were dispersed in $200 \mu$ L Opti-MEM. Cells were given a medium change with $2 \mathrm{~mL}$ of antibiotic free RPMI media with 10\%FBS followed by addition of OptiMEM containing siRPSA@ZIF-C, crRPSA@ZIF-C, EsiRPSA@ZIF-C or EcrRPSA@ZIF-C dropwise in wells and incubated at $5 \% \mathrm{CO}_{2} 37^{\circ} \mathrm{C}$ incubators. After 3.5 hours, the treatment media is replaced 
with $2 \mathrm{~mL}$ of fresh RPMI medium containing 10\%FBS and 1\% antibiotic and continued for incubation for 24, 48, 72 or 96 hours. Cells were then observed under Bio-Rad ZOE ${ }^{\mathrm{TM}}$ fluorescent cell imager (Figure S3) or fixed with 4\% paraformaldehyde, stained with Hoechst nuclear stain and imaged in a confocal laser scanning microscope (Figure 2A-D).
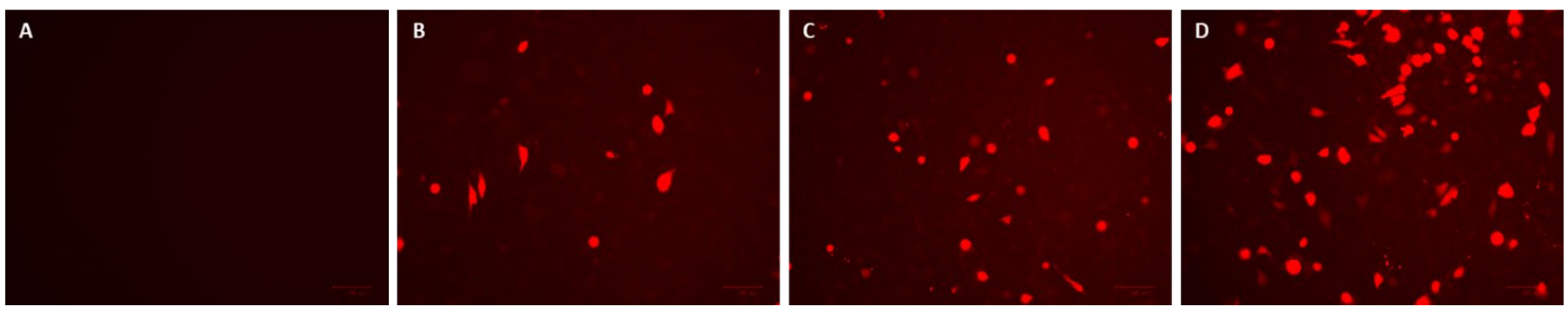

Figure S3. Cellular delivery of CRISPR/Cas9 using ZIF-C. Cell fluorescence imaging of PC3 cells transfected with (A) control untreated cells, (B) crRPSA@ZIF-C, (C) EcrRPSA@ZIF-C and (D) crRPSA@Lipofectamine ${ }^{\mathrm{TM}}$ 3000. All transfections were carried out with 0.49pmols of crRPSA and imaged at 96 hours (A-C) and 24 hours (D). Red - fluorescence due to orange fluorescence protein (OFP) production. Scale bar $100 \mu \mathrm{m}$.

RNAi efficiency by using ZIF-C delivered siRPSA

Total RNA was extracted from control untreated and experimental treated cells using guanidinium phenol reagent (TRIzol reagent; Invitrogen) following manufacturer's protocol. The RNA pellet obtained was dissolved in $30 \mu \mathrm{L}$ DEPC water and purity and concentration were quantified using OPTIZEN NanoQ. Reverse transcription was immediately carried out on $2 \mu \mathrm{g}$ RNA from each sample using High-Capacity cDNA Reverse Transcription Kit (ThermoFisher) following manufacturer's protocol. Reaction was conducted in a T100 ${ }^{\mathrm{TM}}$ Thermal Cycler (BioRad) with the following step details:

\begin{tabular}{|c|l|}
\hline \multicolumn{2}{|c|}{ Lid $105^{\circ} \mathrm{C}$, Reaction vol. $20 \mu \mathrm{l}$} \\
\hline Temperature & Time \\
\hline $1 . \quad 25^{\circ} \mathrm{C}$ & $10: 00$ \\
\hline $2 . \quad 37^{\circ} \mathrm{C}$ & $2: 00: 00$ \\
\hline $3 . \quad 85^{\circ} \mathrm{C}$ & $5: 00$ \\
\hline $4 . \quad 4^{\circ} \mathrm{C}$ & $\infty$ \\
\hline
\end{tabular}


For real time quantitative evaluation of RPSA knockdown using siRNA, qPCR was carried out on the cDNA with RPSA-specific qPCR primers. The TaqMan ${ }^{\mathrm{TM}}$ Fast Universal PCR Master Mix (2X), no AmpErase ${ }^{\mathrm{TM}}$ UNG (ThermoFisher) was used with TaqMan ${ }^{\mathrm{TM}}$ Gene Expression Assay (FAM) ID Hs03046712_g1 (for target RPSA) and Hs01060665_g1 (for housekeeping normalized control ACTB). Manufacturer's protocol was followed, and reaction was conducted in a 7500 Fast Real-Time PCR System (Applied Biosystems) with the following cycle specifications:

\begin{tabular}{|c|l|}
\hline \multicolumn{2}{|l|}{ Reaction vol per well. $10 \mu \mathrm{l}$} \\
\hline Temperature & Time \\
\hline $1.95^{\circ} \mathrm{C}$ & $00: 20$ \\
\hline $2.95^{\circ} \mathrm{C}$ & $00: 03$ \\
\hline $3.60^{\circ} \mathrm{C}$ & $00: 30$ \\
\hline
\end{tabular}

The "fold-over untreated" method was used to calculate the expression level and \%KD of RPSA in treated samples as compared to untreated samples ${ }^{[3]}$.

CRISPR/Cas9 efficiency by using ZIF-8 delivered crRPSA

Untreated, crRPSA@ZIF-C and EcrRPSA@ZIF-C treated PC-3 cells were harvested at 96 hours and lysed using protein degrader in a $\mathrm{T} 100^{\mathrm{TM}} \mathrm{Thermal}$ Cycler $(\mathrm{BioRad})$ at $68^{\circ} \mathrm{C} 15 \mathrm{~min}, 95^{\circ} \mathrm{C} 10 \mathrm{~min}$ and $4^{\circ} \mathrm{C}$ hold. Cell lysate was PCR amplified at the reaction rate of $95^{\circ} \mathrm{C} 10 \min 1 \mathrm{X},\left[95^{\circ} \mathrm{C} 30 \sec 55^{\circ} \mathrm{C}\right.$ (Tm) $30 \mathrm{sec} 40 \mathrm{X}$ Extend $\left.72^{\circ} \mathrm{C} 30 \mathrm{sec}\right] 40 \mathrm{X}, 72^{\circ} \mathrm{C} 7 \mathrm{~min} 1 \mathrm{X}$ hold and $4^{\circ} \mathrm{C}$ hold $1 \mathrm{X}$ using Froward and Reverse primers for the designed oligos. The PCR primers specific to the gRNA sequence were designed using the CRISPR guide-RNA (gRNA) in silico tool 'GeneArt CRISPR Search and Design Tool' from Invitrogen TrueDesign Genome Editor software. The synthesized primer sequences are as follows: 


\begin{tabular}{|c|c|c|c|c|}
\hline $\begin{array}{l}\text { RPSA } \\
- \\
\text { gRNA }\end{array}$ & $\begin{array}{l}\text { gRNA Oligo } \\
\text { Sequence }\end{array}$ & Primer Sequence & $\begin{array}{l}\text { Amplicon Size } \\
\text { (parental band) } \\
\text { for PCR } \\
\text { verification }\end{array}$ & $\begin{array}{l}\text { Cleavage bands } \\
\text { for CRISPR } \\
\text { cleavage } \\
\text { verification }\end{array}$ \\
\hline $\begin{array}{l}\text { R1 } \\
\text { (fwd) }\end{array}$ & $\begin{array}{l}\text { CTATCCTGATACA } \\
\text { TACCAGTGTTTT }\end{array}$ & $\begin{array}{l}\text { CTCAGTGGGTT } \\
\text { TGATGTGGTGG }\end{array}$ & 634 bp & $418+216 b p$ \\
\hline $\begin{array}{l}\text { R1 } \\
\text { (rev) }\end{array}$ & $\begin{array}{l}\text { ACTGGTATGTATC } \\
\text { AGGATAGCGGTG }\end{array}$ & $\begin{array}{l}\text { CTGAGCGCTCC } \\
\text { AGTCTTCTGTT }\end{array}$ & & \\
\hline $\begin{array}{l}\text { R2 } \\
\text { (fwd) }\end{array}$ & $\begin{array}{l}\text { CATAAGCAAATTG } \\
\text { GACGACTGTTTT }\end{array}$ & $\begin{array}{l}\text { GTGCATAAGAA } \\
\text { TTGCCCAG }\end{array}$ & $606 \mathrm{bp}$ & $416+189 b p$ \\
\hline $\begin{array}{l}\mathrm{R} 2 \\
\text { (rev) }\end{array}$ & $\begin{array}{l}\text { AGTCGTCCAATTT } \\
\text { GCTTATGCGGTG }\end{array}$ & $\begin{array}{l}\text { AGTCTGCAACC } \\
\text { TCAGGCT }\end{array}$ & & \\
\hline $\begin{array}{l}\text { R3 } \\
\text { (fwd) }\end{array}$ & $\begin{array}{l}\text { TGCCTGGATCTGG } \\
\text { TTAGTGAGTTTT }\end{array}$ & $\begin{array}{l}\text { GCTGTAGAATG } \\
\text { AACTGAGTG }\end{array}$ & $614 \mathrm{bp}$ & $370+244 b p$ \\
\hline $\begin{array}{l}\text { R3 } \\
\text { (rev) }\end{array}$ & $\begin{array}{l}\text { TCACTAACCAGAT } \\
\text { CCAGGCACGGTG }\end{array}$ & $\begin{array}{l}\text { CTCTAACAATG } \\
\text { TGCACAGGA }\end{array}$ & & \\
\hline
\end{tabular}

Table S2. RPSA targeting CRISPR/Cas9 plasmid details

The resulting PCR product was run on a $2 \%$ agarose gel to verify the presence of a single band corresponding to the amplicon size for the respective gRNA used (Figure S4). A single band is expected to be detected at the same position for treated and untreated cells to confirm target amplification.

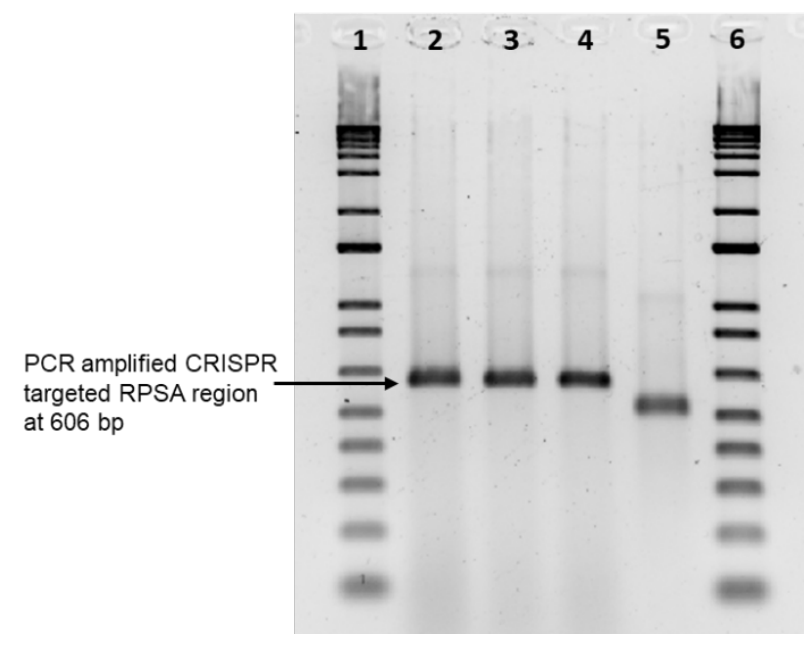

Figure S4. Agarose gel electrophoresis for the verification of PCR amplification of target RPSA genomic region on using RPSA-gRNA-R2. 1, 6 - 1 kbp DNA ladder, 2-crRPSA@ZIF-C, 3 -EcrRPSA@ZIF-C, 4 - untreated and 5 - nonspecific kit control. 
The PCR product was subsequently used for detecting genomic cleavage efficiency, performed by GeneArt $^{\mathrm{TM}}$ Genomic Cleavage Detection Kit (Life Technologies). Cleavage assay was performed by denaturing and reannealing the PCR amplified product to form heterogeneous DNA duplexes using $\mathrm{T} 100^{\mathrm{TM}}$ Thermal Cycler (BioRad) at reaction conditions of $95^{\circ} \mathrm{C} 5 \mathrm{~min}, 95^{\circ} \mathrm{C}-85^{\circ} \mathrm{C}$ [ramp rate $\left.2^{\circ} \mathrm{C} / \mathrm{sec}\right], 85^{\circ} \mathrm{C}-25^{\circ} \mathrm{C}\left[\mathrm{ramp}\right.$ rate $\left.-0.1^{\circ} \mathrm{C} / \mathrm{sec}\right]$ and $4^{\circ} \mathrm{C}$-hold. Immediately, the re-annealed product is proceeded for enzyme digestion by incubating the samples with (or without) the detection enzyme for 1 hour at $37^{\circ} \mathrm{C}$ to detect the heteroduplex DNA containing the insertion, deletion, or mismatched DNA (indel).

Genomic cleavage was visualized by immediately loading the entire enzyme treated sample on a $2 \%$ agarose gel with $10 \mu \mathrm{L}$ water using $1 \mathrm{~kb}$ DNA ladder in parallel as a reference and sample without enzyme treated as negative control and allowed to run at $100 \mathrm{~V}$ for 1 hours. Bands are imaged through Bio-Rad Gel Doc ${ }^{\mathrm{TM}} \mathrm{XR}+$ Imager. Densitometry analysis on the agarose gel obtained bands were quantitated using FIJI ${ }^{[4]}$. In FIJI software, the LUTs were inverted and the rectangle tool was used to isolate the regions of interest. Band intensity peaks were graphed for calculating area under the curve for each peak. The peak percentage of each experimental band (crRPSA@ZIF-8 or EcrRPSA@ZIF-8) was divided by the peak percentage of the control band (nonspecific control) to estimate the relative percent of DNA quantity associated with the crRPSA cleaved bands for determining \%GCD.

\section{Cellular Viability Assay}

Cytotoxicity of siRPSA@ZIF-C, crRPSA@ZIF-C, EsiRPSA@ZIF-C and EcrRPSA@ZIF-C on PC-3 cells were assessed by MTT assay. PC-3 cells were seeded in 96 well plates with density of 10000, 7500,5000 and 2500 cells/well for $24,48,72,96$ hours respectively and incubated at $37^{\circ} \mathrm{C}$ with $5 \% \mathrm{CO} 2$ overnight. Next day cells were treated with $100 \mu \mathrm{L}$ RPMI medium $(10 \% \mathrm{FBS})$ containing test ZIF-C biocomposites (siRPSA@ZIF-C, crRPSA@ZIF-C, EsiRPSA@ZIF-C and EcrRPSA@ZIF-C) and incubated for 3.5 hours at $37^{\circ} \mathrm{C}$ with $5 \% \mathrm{CO} 2$. Then, the medium was replaced with $100 \mu \mathrm{L}$ RPMI medium containing $10 \% \mathrm{FBS}$ and $1 \%$ antibiotic. Later at each time point medium was aspirated in 
respective plate and $100 \mu \mathrm{L}$ of serum free medium containing $0.5 \mathrm{mg} / \mathrm{mL}$ of MTT was added to each well and incubated for 4 hours in dark at $37^{\circ} \mathrm{C}$. After incubation medium containing MTT was replaced with DMSO for dissolving purple formazan crystals and the absorbance was measured in a micro plate reader at $570 \mathrm{~nm}$ with the reference wavelength of $630 \mathrm{~nm}$. The percentage cell viability is calculated by the formula [(absorbance of treated cells/absorbance of untreated cells $) * 100]$.

To check for toxicity of the delivery system, the short chain TAMRA labelled oligomer and a green fluorescent plasmid (plGFP gene) were used to synthesise oligoNA@ZIF-C, geneNA@ZIF-C, EoligoNA@ZIF-C and EgeneNA@ZIF-C (with and without EGCG coating). MTT assays were carried out on PC-3 cells following treatment with these particles in the same protocol as described above (Figure S5). A consistent reduction in viability was seen on treatment with EGCG coated biocomposites as compared to uncoated ones. However, $>80 \%$ viability with uncoated particles and $>70 \%$ viability with coated particles up to 96 hours indicated the lack of significant toxicity from the delivery system itself.

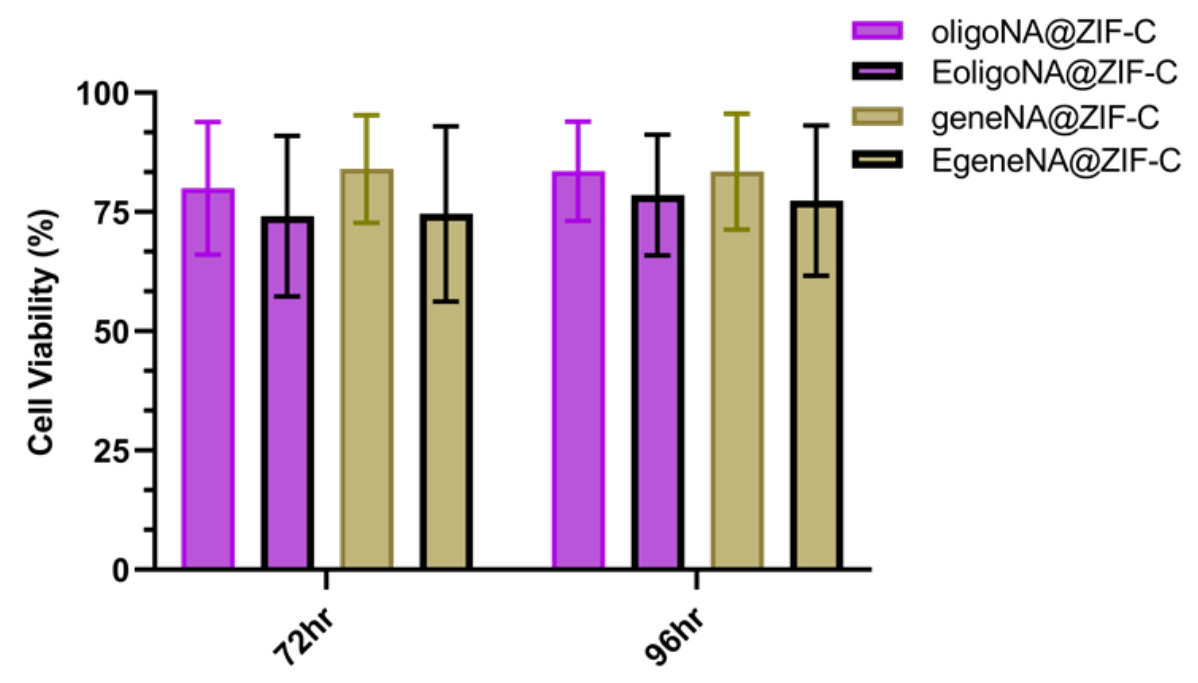

Figure S5. Cellular viability of PC-3 cells after 3.5 hour treatment with non-targeting NA@ZIF-8 biocomposites at 72 and 96 hours.

\section{REFERENCES}

[1] Katsenis AD, Puškarić A, Štrukil V, Mottillo C, Julien PA, Užarević K, Pham M-H, Do T-O, Kimber SAJ, Lazić P, Magdysyuk O, Dinnebier RE, Halasz I, Friščić T. Nature Communications 2015, 6:6662. 
[2] Carraro F, Velasquez M, Astria E, Liang W, Twight 1, parise c, ge m, Huang Z, Ricco R, Zou X, villanova 1, Kappe O, Doonan C, falcaro p. 2019. Available at:

http://europepmc.org/abstract/PPR/PPR101188 https://doi.org/10.26434/chemrxiv.10059935.v1.

[3] Hardikar AA, Farr RJ, Joglekar MV. Journal of the American Heart Association 2014, 3:e000792.

[4] Schindelin J, Arganda-Carreras I, Frise E, Kaynig V, Longair M, Pietzsch T, Preibisch S, Rueden C, Saalfeld S, Schmid B, Tinevez JY, White DJ, Hartenstein V, Eliceiri K, Tomancak P, Cardona A. Nat Methods 2012, 9:676-682. 